\title{
Factors Influencing Nurses' Willingness to Speak Up Regarding Patient Safety in East Asia: A Systematic Review
}

This article was published in the following Dove Press journal: Risk Management and Healthcare Policy

\author{
Seung Eun Lee ${ }^{1,2}$ \\ JiYeon Choi ${ }^{1,2}$ \\ Hyunjie Lee ${ }^{2}$ \\ Somin Sang ${ }^{2}$ \\ Haesun Lee ${ }^{2}$ \\ Hye Chong Hong ${ }^{3}$
}

'Mo-Im Kim Nursing Research Institute, Seoul, South Korea; ${ }^{2}$ College of Nursing, Yonsei University, Seoul, South Korea; ${ }^{3}$ Department of Nursing, Chung-Ang University, Seoul, South Korea
Correspondence: Hye Chong Hong Department of Nursing, Chung-Ang University, 84 Heukseok-ro, Bldg 106 , Dongjak-gu, Seoul, 06974, South Korea Tel +82-2-9278-9106

Fax +82-2-824-796।

Email julieh@cau.ac.kr

\begin{abstract}
Speaking up for patient safety among health care professionals is important because it can contribute to the prevention of adverse patient events, such as medication errors, infections, wrong-site surgical procedures, and other sentinel events. This systematic review identified factors that facilitate or inhibit nurses' willingness to speak up regarding patient safety in East Asian hospitals. Following the steps of the Preferred Reporting Items for Systematic Reviews and Meta-Analyses guidelines, four databases, including PubMed, CINAHL, PsycInfo, and Web of Science, were searched. Nine studies were analyzed in this review, including five qualitative and four quantitative studies published between 2014 and 2019. Quality of included studies were evaluated using the Mixed-Method Appraisal Tool. Data synthesis was based upon qualitative-led synthesis adopting two existing multilevel frameworks on safety voice and employee voice signals. Four studies were conducted in Japan, three in South Korea, one in Hong Kong, and one in Taiwan. We organized factors influencing East Asian nurses' willingness to speak up regarding patient safety according to the following four contexts: individual (motivation toward patient safety, organizational commitment, perceived effectiveness and importance of speaking up, and assertive personality), team (positive relationship and team trust, team culture, and mentoring), organizational (hospital administrative support and organizational culture) and sociocultural (hierarchy and power differential and collectivistic culture). However, due to the limited number of studies conducted in East Asian hospitals, further studies with larger cohort samples of nurses in various East Asian countries should be conducted to deepen our understanding of nurses' willingness to voice their concerns for patient safety.
\end{abstract}

Keywords: assertive communication, voice, silence, having a voice

\section{Introduction}

In recent years, health care professionals' willingness to speak up in clinical settings has received significant attention, as it is essential to enhancing patient safety and quality of care. ${ }^{1}$ Various terms, including assertive communication, speaking up, voice, and employee voice, have been used interchangeably to describe the concept of speaking up. ${ }^{2,3}$ In health care, speaking up for patient safety can be defined as discretionary, change-oriented, and assertive communication in clinical situations using questions or statements with information, concerns, or opinions about safety-related issues. ${ }^{4,5}$ Previous research has shown that health care professionals' choices to speak up can contribute to the prevention of adverse patient events, such as medication errors, infections, wrong-site surgical 
procedures, and other sentinel events. ${ }^{6-8}$ However, despite acknowledging the various benefits resulting from speaking up, health care professionals frequently choose not to voice their concerns and remain silent instead. ${ }^{5}$

Among health care professionals in hospital settings, nurses' close contact with patients grants them a privileged position to observe and address patient safety issues. Further, frontline nurses play an important role in improving patients' safety, as they are well positioned to detect early signs of health hazards, and can bring them to the attention of other medical personnel. ${ }^{2,9,10}$ Therefore, it is vital for clinical nurses to voice their concerns regarding patient safety to prevent harm to patients. However, prior research has shown that nurses voice their concerns less often when they perceive patient safety issues in hospital settings, compared with other health care professionals. ${ }^{1,11}$

Overall, little is known about factors influencing health care professionals' willingness to voice their concerns about patient safety. ${ }^{5}$ However, based on prior organizational literature and a recent review on this subject, ${ }^{4,12}$ nurses' willingness to speak up is influenced by several personal, team, organizational, and sociocultural factors. For example, nurses' fear of being blamed or dismissed if they voice their concerns can affect their willingness to speak up regarding patient safety. ${ }^{2}$ Further, organizational factors such as hospital policies, ${ }^{2}$ organizational culture, ${ }^{4}$ and hierarchies and power dynamics in health care organizations can hinder nurses' willingness to express their concerns or ideas. ${ }^{13}$ In addition, organizational research has demonstrated that sociocultural factors can affect individuals' willingness to speak up, as specific cultures can shape the organizational norms, which in turn can influence an employee's willingness to voice an opinion. ${ }^{12}$ While various factors and contexts can influence nurses' willingness to speak up regarding patient safety, to the best of our knowledge, these elements have not been thoroughly examined in field-relevant literature. Furthermore, the effect of sociocultural context on speaking up should be examined to understand this phenomenon more fully. In a recent literature review, Noort, Reader, and Gillespie ${ }^{4}$ examined the ecological nature of safety voice by reviewing 45 studies conducted in various fields, including health care, most of which were derived from Western countries. However, there are well-documented cultural differences between Western and Eastern countries, so conducting a review of studies from East Asian countries is a necessary next step.
It is reasonable to assume that East Asian countries share similar norms, values, and beliefs. ${ }^{14}$ Deeply rooted in Confucian culture, natural hierarchies are common in various groups and settings in most East Asian cultures. ${ }^{15}$ Because of these hierarchies, speaking up is more challenging in East Asian societies than Western societies, where individual values and voices are more encouraged and accepted. Speaking up and patient safety are concepts that originated in Western culture, so factors contributing to nurses' willingness to speak up might differ in East Asian countries. In addition, previous reviews on speaking up $^{2,4,13}$ have targeted various healthcare professionals, but nurses' experiences about speaking up in healthcare settings could be different from other healthcare professionals, especially from physicians, due to power differentials. ${ }^{16}$ Investigating factors affecting nurses' willingness to speak up in East Asia would expand our understanding of the role of cultural context in this phenomenon. Moreover, findings on this subject will promote the incorporation of cultural contexts into the development of interventions designed to help nurses speak up for patient safety. Therefore, the purpose of this review was to identify factors that influence nurses' willingness to speak up regarding patient safety in East Asian hospital settings.

\section{Methods}

Prior to conducting this review, we searched the International Prospective Register of Systematic Reviews and the Cochrane Library to ensure there has are no prior or ongoing systematic reviews on the topic of speaking up experiences of nurses working in East Asian hospital settings. Our review question identified the following variables of interests: target population (nurses), concept (speaking up), and context (hospitals in East Asian countries). Based on previous literature, in this review, speaking up regarding patient safety referred to informal, discretionary, assertive communication by a nurse about concerns, opinions, suggestions, questions, or information about safety-related issues for their patients to persons who might be able to take appropriate action for changes or improvement. ${ }^{3-5}$ The Preferred Reporting Items for Systematic Reviews and Meta-Analyses (PRISMA) framework $^{17}$ directed the review. We searched the PubMed, CINAHL, PsycInfo, and Web of Science databases using the following keywords and combinations (including indexed terms such as MeSH, CINAHL heading, and text words): employee voice, voice, voice 
behavior, speaking up, silence, withholding voice, assertive communication, and patient safety. An ancestry search was also conducted to identify other eligible articles. The searches were conducted by two reviewers (HJL and HL) who were assisted by an expert in library science in health care. Appendix A shows examples of search strategies used in this review.

Articles were included if they (a) were primary, peerreviewed, scholarly articles concerning nurses speaking up regarding patient safety; (b) included a sample comprising only nurses working in hospital settings; (c) were conducted in East Asian countries; (d) were written in the English language; and (e) were published between 1990 and 2020 to get as wide of a range of studies as possible because, to the best of our knowledge, this is the first review to examine the topic in this context. Studies were excluded if they were (a) conducted outside of a hospital setting; (b) theoretical, discussion, or review articles; (c) focused on incident/error reporting or whistle-blowing to the public rather than speaking $u^{2}$ or (d) focused on communication between health care professionals and patients or their families. ${ }^{2}$

Following database and ancestry searches, 1833 articles were identified. We screened the title and abstract of a total of 1162 non-duplicate articles, after which we excluded 1090 articles. Subsequently, the remaining 72 articles were independently read in full by the two reviewers to assess their eligibility. Following full-text reviews, 63 were excluded, as they did not meet the inclusion criteria. During the literature search process, disagreements between the two reviewers were discussed until a consensus was reached. Finally, nine studies were included in this review. Figure 1 illustrates the PRISMA flow diagram.

We included both quantitative and qualitative articles, all of which were appraised for quality using the MixedMethod Appraisal Tool (MMAT), a critical appraisal tool for systematic mixed studies reviews. ${ }^{18}$ We chose this tool because it is a reliable and efficient tool ${ }^{19}$ that can be used to assess various study designs including quantitative, qualitative, and mixed methods. ${ }^{18}$ This tool has been used in previous systematic reviews that included articles with multiple study designs. ${ }^{20-23}$ The MMAT includes five questions with three possible responses (yes, no, or cannot tell) for quantitative, qualitative, and mixed methods studies. Using the appropriate category in the MMAT based on each article's study design, two reviewers (HJL and HL) independently conducted quality assessments that were then reviewed by another reviewer (SS). If any disagreements surfaced, the reviewers discussed their assessments until they reached a consensus. The overall score for each criterion was not calculated, as recommended by the MMAT guidelines (See Appendix B for MMAT ratings). ${ }^{18}$

Three reviewers (HJL, HL, and SS) independently extracted data from all included articles, and disagreements among them were discussed until a consensus was reached. During the final review, the results of each study were organized using a matrix with the following information: author, year, country, study aims, methods, sampling and setting, speaking up or silence definition, main results, and limitations. For quantitative studies, information regarding independent/dependent variables and their measurements was also extracted. Additionally, the research team extracted themes and findings from qualitative studies. The extracted data were then validated by another reviewer $(\mathrm{SL})$.

Data synthesis was based upon qualitative-led synthesis adopting two existing multilevel frameworks on safety voice $^{4}$ and employee voice signals. ${ }^{12}$ Extracted data were synthesized by identification, coding, and thematic grouping of factors influencing nurses' willingness to speak up and its consequences, and these were integrated into multilevel contexts as individual, team, organization, or societal contexts.

\section{Results}

\section{Characteristics of Studies Reviewed}

As shown in Table 1, nine studies were analyzed in this review, including five qualitative studies and four quantitative studies, published between 2014 and 2019. Four studies were conducted in Japan, ${ }^{24-27}$ three in South Korea, ${ }^{28-30}$ one in Hong Kong, ${ }^{31}$ and one in Taiwan. ${ }^{32}$ The number of nurses in the qualitative studies ranged from 3 to 23 and the number of nurses in the quantitative studies ranged from 247 to 988 . Although some studies included samples of nurses and nurse managers, the majority of the samples (78\% or higher) were staff nurses. Other sample characteristics, such as age and years of nursing experience, were reported in different forms in the studies reviewed (see Table 1). The number of hospitals varied from one to five; however, four studies ${ }^{25-27,29}$ did not mention the number of hospitals involved in data collection. According to the MMAT ratings, eight studies satisfied $100 \%$ of the criteria and one study ${ }^{30}$ met $60 \%$ (Appendix B). 


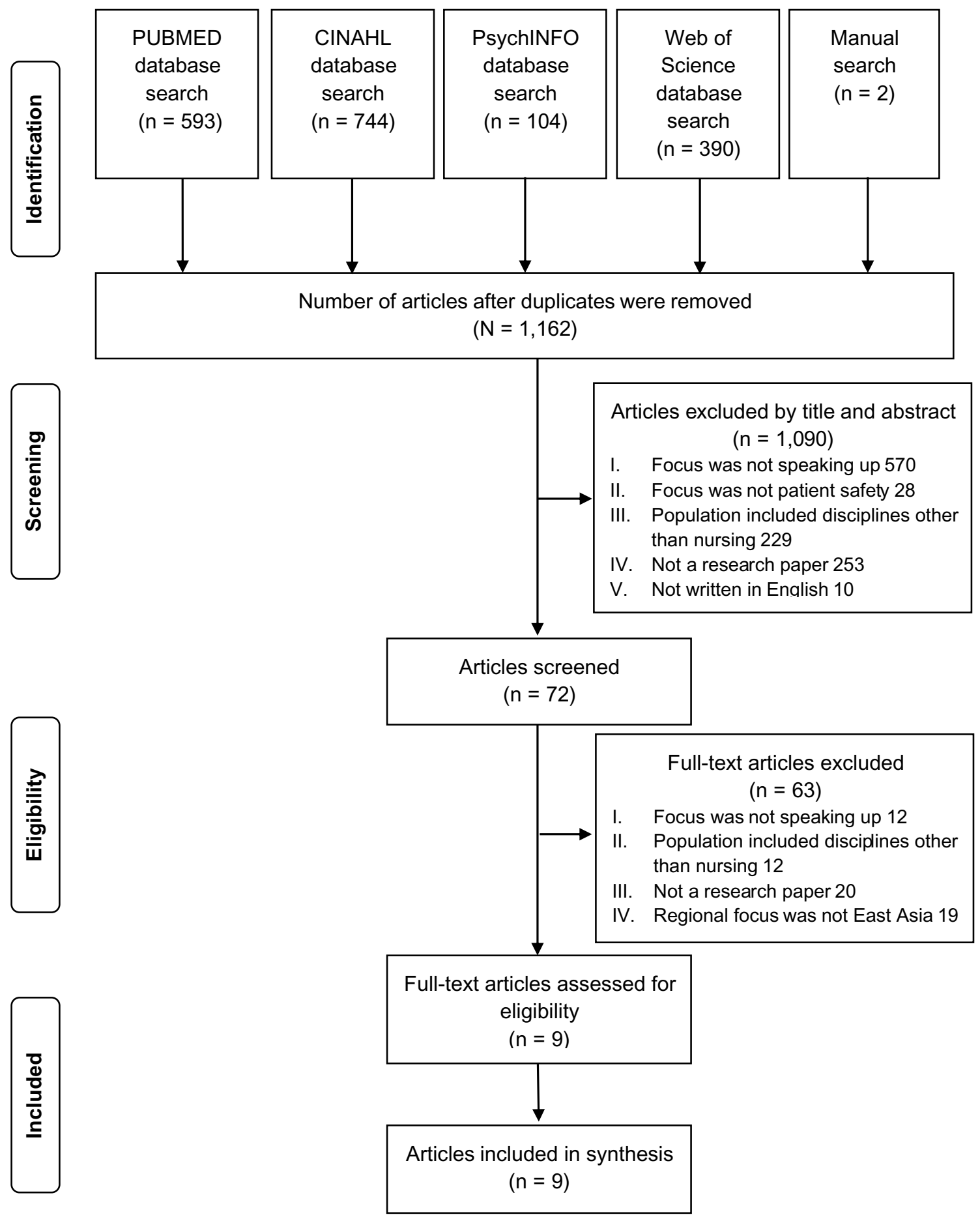

Figure I PRISMA flow diagram illustrating selection of studies for review.

Notes: PRISMA figure adapted from Liberati A, Altman D, Tetzlaff J, et al. The PRISMA statement for reporting systematic reviews and meta-analyses of studies that evaluate health care interventions: explanation and elaboration. Journal of clinical epidemiology. 2009;62(10). Creative Commons. ${ }^{18}$

Factors Influencing Nurses' Willingness to Speak Up Regarding Patient Safety

As shown in Table 2, adopting two multilevel frameworks for employee voice, ${ }^{4,12}$ we summarized factors promoting or inhibiting nurses' decision to speak up regarding patient safety in four contexts: sociocultural, organizational, team, and individual. In this review, we used the term context rather than level because the unit of analysis in the studies reviewed was the individual level. The sociocultural context included hierarchy, 
Table I Summary of Studies Reviewed

\begin{tabular}{|c|c|c|c|c|c|}
\hline Study & Aim/Methodology & Sample/Setting & $\begin{array}{l}\text { Definition of Speaking } \\
\text { up/Silence }\end{array}$ & $\begin{array}{l}\text { Speaking up/ } \\
\text { Silence Measure }\end{array}$ & Main results \\
\hline [24] & $\begin{array}{l}\text { A quantitative study } \\
\text { examining nurses' } \\
\text { speaking-up attitudes and } \\
\text { behaviors using cluster } \\
\text { analysis }\end{array}$ & $\begin{array}{l}\mathrm{N} \text { nurses (staff nurses and nurse } \\
\text { managers) }=788 \\
\text { Age }=\mathrm{NR} \\
\text { Nursing experience (year) }=10.7 \\
\text { (mean) } \\
\mathrm{N} \text { hospitals }=3 \\
\text { Japan }\end{array}$ & $\begin{array}{l}\text { Raising of concerns by } \\
\text { health care professionals } \\
\text { for the benefit of patient } \\
\text { safety and care quality } \\
\text { upon recognizing or } \\
\text { becoming aware of the } \\
\text { risky or deficient actions of } \\
\text { others within health care } \\
\text { teams } 2,49,50\end{array}$ & $\begin{array}{l}\text { Two items used to } \\
\text { measure the } \\
\text { frequency of being } \\
\text { aware of risky } \\
\text { behavior and } \\
\text { experience of } \\
\text { speaking-up in the } \\
\text { previous month }\end{array}$ & $\begin{array}{l}\text { Team relationship, seniors' attitudes, } \\
\text { assertiveness, organizational } \\
\text { commitment, and perceived importance } \\
\text { and effectiveness of speaking up were } \\
\text { positively related to nurses' speaking-up } \\
\text { behavior. } \\
\text { Negative attitudes toward voicing } \\
\text { opinions within the health care team and } \\
\text { perceived personal negative } \\
\text { consequences of speaking-up were } \\
\text { negatively associated with nurses' } \\
\text { speaking-up behavior. } \\
\text { No significant relationship was found } \\
\text { between hospital administrative support } \\
\text { and nurses' speaking-up behavior. }\end{array}$ \\
\hline [25] & $\begin{array}{l}\text { A qualitative study } \\
\text { exploring how culture and } \\
\text { values impact assertive } \\
\text { communication of Japanese } \\
\text { nurses }\end{array}$ & $\begin{array}{l}\mathrm{N} \text { nurses (staff nurses and nurse } \\
\text { managers) }=23 \\
\text { Age (year) }=21-30 \\
\text { Nursing experience (year) }=|-2| \\
\mathrm{N} \text { hospitals }=\mathrm{NR} \\
\text { Japan }\end{array}$ & $\begin{array}{l}\text { Being able to respectfully } \\
\text { express their opinions and } \\
\text { concerns regarding patient } \\
\text { care to other healthcare } \\
\text { professionals, including } \\
\text { those in authority } 46,51\end{array}$ & NA & $\begin{array}{l}\text { Themes identified: 'Wa (harmony), Uchi } \\
\text { to soto (inside and outside), implicit } \\
\text { communication/ambiguity, } \\
\text { Nemawash (groundwork) }\end{array}$ \\
\hline [26] & $\begin{array}{l}\text { A qualitative study } \\
\text { exploring how cultural } \\
\text { values influence Japanese } \\
\text { nurses' assertive } \\
\text { communication behaviors } \\
\text { and attitudes }\end{array}$ & $\begin{array}{l}\mathrm{N} \text { nurses (staff nurses and nurse } \\
\text { managers) }=23 \\
\text { Age (year) }=21-30 \\
\text { Nursing experience (year) }=|-2| \\
\mathrm{N} \text { hospitals }=\mathrm{NR} \\
\text { Japan }\end{array}$ & $\begin{array}{l}\text { Being able to respectfully } \\
\text { express their opinions and } \\
\text { concerns regarding patient } \\
\text { care to other health-care } \\
\text { professionals, including } \\
\text { those in authority } 46,51\end{array}$ & NA & $\begin{array}{l}\text { Themes identified: } \\
\text { collectivism, hierarchy/power }\end{array}$ \\
\hline [27] & $\begin{array}{l}\text { A qualitative study to } \\
\text { explore perceptions of the } \\
\text { relevance and use of } \\
\text { assertive communication } \\
\text { and to identify factors } \\
\text { influencing assertive } \\
\text { communication of Japanese } \\
\text { nurses }\end{array}$ & $\begin{array}{l}\mathrm{N} \text { nurses (staff nurses and nurse } \\
\text { managers) }=23 \\
\text { Age (year) }=2 \mid-30 \\
\text { Nursing experience (year) }=|-2| \\
\mathrm{N} \text { hospitals = NR } \\
\text { Japan }\end{array}$ & $\begin{array}{l}\text { Being able to respectfully } \\
\text { express their opinions and } \\
\text { concerns regarding patient } \\
\text { care to other healthcare } \\
\text { professionals, including } \\
\text { those in authority } 46,51\end{array}$ & NA & $\begin{array}{l}\text { Facilitators of assertive communications } \\
\text { were supportive environment, positive } \\
\text { relationships, effective role models, } \\
\text { experience/knowledge about speaking up, } \\
\text { and motivation to provide person- } \\
\text { centered care. } \\
\text { Inhibitors of assertive communication } \\
\text { were strict hierarchies, age-based } \\
\text { seniority, concerns regarding offending } \\
\text { colleagues, and disrupting team harmony. } \\
\text { Consequences of not being assertive: } \\
\text { internal discontent, situational discord } \\
\text { between staff, and patient deterioration }\end{array}$ \\
\hline [28] & $\begin{array}{l}\text { A quantitative study } \\
\text { developing a hypothetical } \\
\text { model that explains nurses' } \\
\text { silence regarding patient } \\
\text { safety }\end{array}$ & $\begin{array}{l}\mathrm{N} \text { nurses }=309 \\
\text { Age }(\text { year) }=29.94 \text { (mean) } \\
\text { Nursing experience (month) }=72.69 \\
\text { (mean) } \\
\mathrm{N} \text { hospitals }=5 \\
\text { South Korea }\end{array}$ & $\begin{array}{l}\text { Setting of actions with } \\
\text { which organizational } \\
\text { members maintain silence } \\
\text { in situations related to } \\
\text { patient safety }\end{array}$ & $\begin{array}{l}\text { Defensive silence } \\
\text { scale }^{52} \text { modified to } \\
\text { capture employee } \\
\text { silence in the } \\
\text { context of patient } \\
\text { safety in the hospital } \\
\text { by Tangirala and } \\
\text { Ramanujam } \\
53\end{array}$ & $\begin{array}{l}\text { Nurse-physician collaboration, } \\
\text { supervisory trust, and patient safety } \\
\text { motivation had a negative association } \\
\text { with silence regarding patient safety. } \\
\text { Organizational culture and patient safety } \\
\text { attitude did not have significant } \\
\text { associations with silence regarding patient } \\
\text { safety. }\end{array}$ \\
\hline [29] & $\begin{array}{l}\text { A qualitative study } \\
\text { generating a model that } \\
\text { explains the } \\
\text { communication processes } \\
\text { of nurses in clinical settings } \\
\text { in South Korea }\end{array}$ & $\begin{array}{l}\mathrm{N} \text { nurses }=15 \\
\text { Age }(\text { year })=31.6 \text { (mean) } \\
\text { Nursing experience }(\text { month })=90.6 \\
\text { (mean) } \\
\mathrm{N} \text { hospitals = NR } \\
\text { South Korea }\end{array}$ & NR & NA & $\begin{array}{l}\text { Themes identified: } \\
\text { getting to know unspoken rules, } \\
\text { persevering within the culture, acting as a } \\
\text { senior nurse }\end{array}$ \\
\hline
\end{tabular}

(Continued) 
Table I (Continued).

\begin{tabular}{|c|c|c|c|c|c|}
\hline Study & Aim/Methodology & Sample/Setting & $\begin{array}{l}\text { Definition of Speaking } \\
\text { up/Silence }\end{array}$ & $\begin{array}{l}\text { Speaking up/ } \\
\text { Silence Measure }\end{array}$ & Main results \\
\hline [30] & $\begin{array}{l}\text { A quantitative study } \\
\text { examining the factors } \\
\text { influencing nurses' } \\
\text { willingness to report near } \\
\text { misses }\end{array}$ & $\begin{array}{l}\mathrm{N} \text { nurses }=498 \\
\text { Age }(\text { year })=28.8 \text { (mean) } \\
\text { Nursing experience }(\text { year })=5.8 \\
\text { (mean) } \\
\mathrm{N} \text { hospitals }=1 \\
\text { South Korea }\end{array}$ & $\begin{array}{l}\text { Conscious and progressive } \\
\text { attitude adopted to protect } \\
\text { oneself from possible } \\
\text { disadvantages }\end{array}$ & $\begin{array}{l}\text { Defensive silence } \\
\text { scale }^{52}\end{array}$ & $\begin{array}{l}\text { Defensive silence was negatively } \\
\text { associated with nurses' willingness to } \\
\text { report near misses. } \\
\text { Knowledge-sharing climate moderated } \\
\text { the association between defensive silence } \\
\text { and willingness to report near misses. }\end{array}$ \\
\hline [31] & $\begin{array}{l}\text { A qualitative study } \\
\text { exploring the process of } \\
\text { learning to speak up } \\
\text { among newly-graduated } \\
\text { nurses }\end{array}$ & $\begin{array}{l}\mathrm{N} \text { nurses }=3 \\
\text { Age }=\mathrm{NR} \\
\text { Nursing experience }=\mathrm{NR} \\
\mathrm{N} \text { hospitals }=1 \\
\text { Hong Kong }\end{array}$ & $\begin{array}{l}\text { Using voice to convey } \\
\text { specific information that } \\
\text { might make a difference to } \\
\text { patient safety to someone } \\
\text { with higher authority }{ }^{54}\end{array}$ & NA & $\begin{array}{l}\text { Themes identified: } \\
\text { learning to speak up requires more than } \\
\text { one-off training and safety tools, } \\
\text { mentoring speaking up in the midst of } \\
\text { educative and miseducative experiences, } \\
\text { making public spaces safe for telling } \\
\text { secret stories }\end{array}$ \\
\hline [32] & $\begin{array}{l}\text { A quantitative study to } \\
\text { examine associations } \\
\text { between team trust, team- } \\
\text { based self-esteem, and } \\
\text { voice behavior of nurses } \\
\text { and to explore the } \\
\text { moderating effect of } \\
\text { power distance orientation } \\
\text { in the relationships }\end{array}$ & $\begin{array}{l}\mathrm{N} \text { nurses }=247 \\
\text { Age (year) }=35.57 \text { (mean) } \\
\text { Nursing experience (year) = over } 6 \\
\text { (mean) } \\
\mathrm{N} \text { hospitals }=1 \\
\text { Taiwan }\end{array}$ & $\begin{array}{l}\text { Behavior that challenges } \\
\text { the status quo with } \\
\text { constructive suggestions or } \\
\text { opinions for one's own } \\
\text { benefits, even in a } \\
\text { dissenting situation }{ }^{55,56}\end{array}$ & $\begin{array}{l}\text { Six items from the } \\
\text { Helping and voice } \\
\text { extra-role } \\
\text { behaviors }^{57}\end{array}$ & $\begin{array}{l}\text { Team trust was positively associated with } \\
\text { nurses' voice behavior. } \\
\text { Team-based self-esteem partially mediates } \\
\text { the association between team trust and } \\
\text { voice behavior. } \\
\text { Power orientation distance moderated } \\
\text { the indirect effect of team trust on voice } \\
\text { behavior through team-based self-esteem. }\end{array}$ \\
\hline
\end{tabular}

Abbreviations: N, number; NR, not reported; NA, not applicable.

power differentials, and collectivistic culture. The organizational context consisted of hospital administrative support for patient safety and organizational culture. The team context included positive relationships and team trust, team culture, and mentoring. Finally, the individual context included motivation toward patient safety, organizational commitment, perceived effectiveness and importance of speaking up, and assertiveness.

\section{Sociocultural Context}

\section{Hierarchy and Power Differential}

Age-based seniority, seniority-based hierarchy, and genderand profession-based power differentials inhibited nurses'

Table 2 Factors Influencing Nurses' Speaking Up and Remaining Silent

\begin{tabular}{|c|c|c|c|}
\hline \multirow[t]{2}{*}{ Context } & \multirow[t]{2}{*}{ Factor } & \multicolumn{2}{|c|}{ Association with Outcome } \\
\hline & & Speaking Up & Remaining Silent \\
\hline Sociocultural & $\begin{array}{l}\text { Hierarchy and power differential } \\
\text { Collectivistic culture }\end{array}$ & $\begin{array}{l}\text { Inhibiting }{ }^{26,27,29,31} \\
\text { Inhibiting } \\
25,29,31\end{array}$ & $\begin{array}{l}\text { Promoting } \\
\text { Promoting }^{29}\end{array}$ \\
\hline Organizational & $\begin{array}{l}\text { Hospital administrative support } \\
\text { Organizational culture }\end{array}$ & Not significant ${ }^{24}$ & Not significant ${ }^{28}$ \\
\hline Team & $\begin{array}{l}\text { Positive relationship and team trust } \\
\text { Team culture } \\
\text { Mentoring }\end{array}$ & $\begin{array}{l}\text { Promoting } \\
\text { Promoting } \\
\text { 24,27,27,29,31 } \\
\text { Promoting } \\
\text { 27,31 }\end{array}$ & Inhibiting $^{28}$ \\
\hline Individual & $\begin{array}{l}\text { Motivation towards patient safety } \\
\text { Organizational commitment } \\
\text { Perceived effectiveness and importance } \\
\text { Assertiveness }\end{array}$ & $\begin{array}{l}\text { Promoting }{ }^{24} \\
\text { Promoting } \\
\text { Promoting } \\
\text { Pr }\end{array}$ & Inhibiting ${ }^{28}$ \\
\hline
\end{tabular}


willingness to speak up and promoted silence. ${ }^{26,27,29,31}$ A hierarchical relationship, which is determined by age rather than competence, impaired junior nurses' willingness to speak up, ${ }^{29}$ even when they were aware of threats to patients' safety, because the act of speaking up was considered imprudent, especially to senior health care personnel. ${ }^{26,27}$ Moreover, hierarchical relationships, when coupled with indirect communication styles, made junior nurses hesitant to voice their concerns or ideas. Implicit communication is typical in Korean and Japanese culture; thus, junior nurses are expected to anticipate implicit intentions and messages from their seniors even if the communication is not clear or straightforward. ${ }^{25,27,29}$ Further, nurses reported that speaking up was difficult due to the power differential. In general, physicians are considered to have more power than nurses in work settings; therefore, nurses' willingness to speak up is often restricted by the power of physicians. ${ }^{26,27,29}$ Furthermore, gender norms frequently discourage female nurses from being assertive. They often have difficulty speaking up when in the presence of male health care providers due to a culture that expects women to be non-confrontational. ${ }^{26}$ Such inherent cultural and social norms often discourage nurses from speaking up.

\section{Collectivistic Culture}

Collectivistic cultures put more value on group identities and group benefits over personal achievements. ${ }^{12}$ In a collectivistic culture, the maintenance of harmonious working relationships is more valued than expressing ones' ideas, which makes it difficult for nurses to speak up. ${ }^{25,29,31}$

\section{Organizational Context}

Hospital Administrative Support and Organizational Culture One Japanese study examined the relationship between hospital administrative support for patient safety and nurses' speaking up behaviors, and found no statistically significant relationships between them. ${ }^{24}$ One Korean study found that nurse-perceived organizational culture had no influence on nurses' silence regarding patient safety. ${ }^{28}$

\section{Team Context}

\section{Positive Relationships and Team Trust}

Several studies showed that positive relationships among nursing staff and between nurses and physicians, as well as nurses' trust in their team, influence nurses' willingness to speak up. For example, nurses' perceived sense of belonging to their teams and their relationship with their peers both positively affect their willingness to speak up..$^{25,27,29}$ Nurses who reported having better working relationships with physicians were more likely to speak up regarding patient safety. ${ }^{28}$ In addition, as nurses trusted their team more and felt more confident that they were valuable to the team, they were more apt to express their concerns, ideas, and opinions. ${ }^{32}$ Nurses were more likely to speak up regarding patient safety when they had higher levels of trust in their relationship with supervisors. ${ }^{28}$

\section{Team Culture}

Team culture supports an environment where being assertive is acceptable, which promoted nurses' willingness to speak up. An environment where senior nurses and managers attentively take junior nurses' opinions into consideration is conducive to nurses' willingness to voice their thoughts and concerns. ${ }^{24,29}$ Previous studies reported that nurses spoke up more when their managers and senior colleagues showed a supportive attitude toward their voice and contributions, which created an environment where their voice was perceived as safe and effective. ${ }^{27,31}$ Conversely, a team culture that does not support assertive communication causes nurses to perceive speaking up as unsafe and ineffective. When nurses felt that their voices were ignored or rejected by peers and/or senior health care professionals, they avoided speaking up, as they felt doing so was unsafe and even futile. ${ }^{29,31}$ Specifically, being ignored by team members without any explanation prevented nurses from voicing their opinions or concerns regarding patient safety. ${ }^{31}$

\section{Mentoring}

Mentors can be a variety of individuals, including senior health care professionals, managers, colleagues, and physicians in a team. ${ }^{31}$ As an educational experience, mentoring influenced nurses' willingness to speak up even when they felt that voicing their concerns was unsafe or ineffective. ${ }^{31}$ In addition, nurses felt more at ease toward speaking up when they had effective role models who were assertive and showed that voicing one's thoughts or concerns was an important aspect of health care. ${ }^{27,31}$

\section{Individual Context}

Several individual factors influenced nurses' willingness to speak up. Nurses' motivation toward patient safety inhibited their silence. ${ }^{28}$ Nurses who were more committed to their organizations tended to voice their thoughts and concerns more frequently. ${ }^{24}$ In addition, nurses' perceived effectiveness and importance of speaking up and assertiveness were positively related to how often they spoke up. ${ }^{24}$ 


\section{Consequences of Not Speaking Up}

Two studies reported the nurse-perceived consequences of not speaking up. Nurses felt that not speaking up made them miss a chance to exchange proper information for patient care, which could cause a patient's condition to deteriorate. ${ }^{27}$ Nurses reported emotional reactions, such as feelings of regret, discontent, stress, and worry, as a consequence of not speaking up. ${ }^{27}$ Furthermore, higher levels of nurse silence were negatively related to their willingness to report near misses. ${ }^{30}$

\section{Discussion}

This systematic review aimed to identify factors influencing nurses' willingness to speak up regarding patient safety in East Asian hospitals. We found that not only individual, team, and organizational factors, but also broader sociocultural factors influenced nurses' willingness to voice their thoughts and concerns.

According to our findings, sociocultural characteristics play a significant role in nurses' willingness to speak up; these include age- and seniority-based hierarchies, ${ }^{26,27,29,31}$ power differentials between professions and genders, ${ }^{26,27,29}$ and collectivistic culture. ${ }^{25-27,29,31}$ In general, Asian cultures place a significant emphasis on seniority. ${ }^{26}$ Even though there is no clear definition of seniority in the literature, it is generally understood as a system defined by age differences between individuals, paternalism, and the ideas of Confucianism that emphasize the importance of respecting one's elders. ${ }^{34}$ Compared to Western countries, in which positional hierarchy is not affected by the age of employees, in Japan and Korea, seniority is determined by age and job longevity. Therefore, employees who are older and have been working longer in a specific position or institution are more respected and their opinions are highly valued. ${ }^{26,34} \mathrm{In}$ these cultures, it is difficult for junior staff to raise their concerns or opinions to their managers and senior colleagues, even when they notice unsafe situations that could negatively impact patient safety. Furthermore, gender and professional power imbalance can adversely affect nurses' willingness to speak up. In a strongly hierarchical culture, the power imbalance between men and women, and physicians and nurses, is significant, ${ }^{35}$ which makes female nurses more hesitant to speak up and less likely to assertively voice their ideas or concerns. ${ }^{13}$ Lastly, East Asian cultures generally consider group goals and values more important than those of the individual. ${ }^{36}$ In collectivist cultures like these, interconnectedness between group members shapes their identity, opinions, and thoughts, while individuality is not encouraged unless the majority of group members allows it. ${ }^{37}$ Such strong hierarchies and collectivistic culture in East Asia can hinder nurses' willingness to voice their thoughts, opinions, and concerns.

In this review, we found that open and supportive leaders were conducive to nurses' willingness to speak up. Based on this finding, we suggest that hospital administrators and nurse leaders should find ways to motivate and empower nurses to openly express their thoughts and concerns. According to findings from previous research, one promising way to encourage nurses to speak up is by establishing and developing their feeling of psychological safety, ${ }^{8,38}$ which is "a shared belief that the team is safe for interpersonal risk taking." ${ }^{\text {39(p.354.) }}$ Researchers have emphasized that the behaviors of managers or supervisors can help develop a psychologically safe environment that can encourage their employees to speak up., ${ }^{8,38}$ Subordinates' psychological safety can be promoted by leaders' inclusive behaviors, ${ }^{40}$ which are characterized by clear exhibition of openness, availability, and accessibility. ${ }^{41}$ Inclusive leaders actively invite others to voice their opinions and show appreciation for them, thus allowing their subordinates to believe that their voices are heard and sincerely valued ${ }^{42}$ in so doing, inclusive leaders facilitate greater psychological safety among their staff. ${ }^{16,41}$ Simultaneously, support from the organizational level is necessary, for example, realigning the organization's policies to be consistent with a new culture and providing physical space or services to promote staff engagement. ${ }^{43}$ Driving changes at the organizational level is challenging but indispensable to expedite and sustain the new culture.

This review demonstrated that hierarchical culture was one of major barrier for nurses to speak up in East Asian hospital settings. Overall, in East Asian cultures, people are prone to adopt indirect communication styles rather than direct verbal communication, and words are understood more in context than in their literal meaning. ${ }^{44}$ Further, understanding meaning through context alone without asking directly is often regarded as a virtue. Thus, hierarchical relationships coupled with indirect communication styles might lead nurses to stop voicing their concerns about patient safety. Although limited, studies have examined the effectiveness of assertiveness training for nurses. For example, Yoshinaga et $\mathrm{al}^{45}$ conducted assertiveness training that consisted of two 90-minute training sessions and demonstrated that it was effective 
for the long-term enhancement of assertiveness among nurses in Japan. Additionally, Omura et $\mathrm{al}^{46}$ conducted a literature review on the effectiveness of assertiveness training programs for health care professionals and students; this review included eight studies (seven of which were conducted in Western countries) and showed the sustained effect of assertiveness in nurses and nursing and medical students. Providing such trainings may be beneficial for East Asian nurses to develop assertive communication skills.

In general, studies on employee voice have been conducted primarily in Western countries. ${ }^{2}$ However, as cultural contexts can influence staff voice or silence, ${ }^{12}$ future studies should explore how sociocultural factors interact with nurses' willingness to voice their thoughts and concerns in East Asia. Further, in this review, we determined that measures regarding nurses' speaking up used in three quantitative studies were originally developed in Western countries, but only one study ${ }^{28}$ detailed a discussion on the cross-cultural adaptation and validation of its measures. When a translated version of an instrument is used in another cultural context, cross-cultural validation is necessary to demonstrate whether the tool is applicable in other cultures. ${ }^{47,48}$ This is because a concept, which is measured by subjective perceptions that are based on personal experiences, could have different meanings in different cultures. Thus, instruments developed in Western countries may be inadequate to properly measure employee voice or silence in an East Asian cultural context. Therefore, future studies should conduct a rigorous cross-cultural adaptation and validation process of their tools if they are being used in cultural contexts different from which said tools were developed. Moreover, we suggest that future research should expand its sampling, settings, and regions beyond Western countries to better understand the role of sociocultural contexts in determining nurses' willingness to speak up at the global level. This is particularly important because the international migration of health care professionals, especially nurses, has increased cultural diversity among hospital employees.

This systematic review had several limitations. Some studies may have been overlooked due to the fact that a variety of terms are used to refer to speaking up. ${ }^{2} \mathrm{We}$ used various search terms and their combinations, but we were unable to improve the sensitivity of these parameters during our literature review. Moreover, we may have missed relevant studies because we limited our search to studies published in English. Finally, due to the small number of studies reviewed, generalizing our results might prove difficult. Nevertheless, this review improves the understanding of nurses' willingness to speak up regarding patient safety in East Asian hospitals.

\section{Conclusion}

This review provided information about factors associated with nurses' willingness to voice their thoughts and concerns regarding patient safety in East Asian hospitals. The reviewed studies indicated that individual, team, organizational, and sociocultural factors influenced nurses' willingness to speak up. This review demonstrated that Asian sociocultural characteristics (such as age- and seniority-based hierarchies, collectivistic culture, and professional and gender differences) make nurses hesitant to voice their concerns about patient safety. We found that open and supportive leaders play a vital role in supporting nurses' willingness to speak up when they had concerns, ideas, questions, or suggestions related to patient care. Health care and nursing leaders should understand which factors facilitate or impede nurses' willingness to speak up regarding patient safety; they should also implement strategies to effectively motivate and empower East Asian nurses to voice their concerns, which could, in turn, improve patient safety in health care systems.

\section{Author Contributions}

All authors made a significant contribution to the work reported, whether that was in the conception, study design, execution, acquisition of data, analysis and interpretation, or in all these areas; took part in drafting, revising, or critically reviewing the article; gave final approval of the version to be published; agreed on the journal to which the article has been submitted; and agree to be accountable for all aspects of the work.

\section{Funding}

This work was supported by the National Research Foundation of Korea (NRF) grant funded by the Korea government (MSIT) (No. 2020R1C1C1006993) and the faculty research funding by Yonsei University College of Nursing. No funding body had a role in the study design and collection, analysis, and interpretation of data and in manuscript writing.

\section{Disclosure}

The authors report no conflicts of interest in this work. 


\section{References}

1. Schwappach D, Richard A. Speak up-related climate and its association with healthcare workers' speaking up and withholding voice behaviours: a cross-sectional survey in Switzerland. BMJ Qual Saf. 2018;27(10):827-835. doi:10.1136/bmjqs-2017-007388

2. Okuyama A, Wagner C, Bijnen B. Speaking up for patient safety by hospital-based health care professionals: a literature review. $B M C$ Health Serv Res. 2014;14(1):61. doi:10.1186/1472-6963-14-61

3. Morrison EW. Employee voice and silence. Annu Rev Organ Psychol Organ Behav. 2014;1(1):173-197. doi:10.1146/annurev-orgpsych -031413-091328

4. Noort MC, Reader TW, Gillespie A. Speaking up to prevent harm: a systematic review of the safety voice literature. Saf Sci. 2019;117:375-387. doi:10.1016/j.ssci.2019.04.039

5. Schwappach DLB, Gehring K. Trade-offs between voice and silence: a qualitative exploration of oncology staff's decisions to speak up about safety concerns. BMC Health Serv Res. 2014;14(1):303. doi:10.1186/1472-6963-14-303

6. Szymczak JE. Infections and interaction rituals in the organisation: clinician accounts of speaking up or remaining silent in the face of threats to patient safety. Sociol Health Illn. 2016;38(2):325-339. doi:10.1111/1467-9566.12371

7. Hémon B, Michinov E, Guy D, Mancheron P, Scipion A. Speaking up about errors in routine clinical practice: a simulation-based intervention with nursing students. Clin Simul Nurs. 2020;45:32-41. doi:10.1016/j.ecns.2020.03.003

8. Alingh $\mathrm{CW}$, van Wijngaarden JDH, van de Voorde K, Paauwe J, Huijsman R. Speaking up about patient safety concerns: the influence of safety management approaches and climate on nurses' willingness to speak up. BMJ Qual Saf. 2019;28(1):39-48. doi:10.1136/bmjqs2017-007163

9. Chua WL, Mackey S, Ng EKC, Liaw SY. Front line nurses' experiences with deteriorating ward patients: a qualitative study. Int Nurs Rev. 2013;60(4):501-509. doi:10.1111/inr.12061

10. Massey D, Chaboyer W, Anderson V. What factors influence ward nurses' recognition of and response to patient deterioration? An integrative review of the literature. Nurs Open. 2017;4(1):6-23. doi:10.1002/nop2.53

11. Schwappach DLB, Niederhauser A. Speaking up about patient safety in psychiatric hospitals - a cross-sectional survey study among healthcare staff. Int J Ment Health Nurs. 2019;28(6):1363-1373. doi:10.1111/inm.12664

12. Kwon B, Farndale E. Employee voice viewed through a cross-cultural lens. Hum Resour Manag Rev. 2020;30(1):100653. doi:10.1016/j.hrmr.2018.06.002

13. Morrow KJ, Gustavson AM, Jones J. Speaking up behaviours (safety voices) of healthcare workers: a metasynthesis of qualitative research studies. Int $J$ Nurs Stud. 2016;64:42-51. doi:10.1016/j. ijnurstu.2016.09.014

14. Fujita S, Seto K, Ito S, Wu Y, Huang CC, Hasegawa T. The characteristics of patient safety culture in Japan, Taiwan and the United States. BMC Health Serv Res. 2013;13(1):20. doi:10.1186/14726963-13-20

15. Liu Z. The influence of confucianism on East Asian countries. $A d v$ Social Sci Educ Humanit Res. 2018;232:77-79. doi:10.2991/icadce18.2018 .14

16. Edmondson AC, Lei Z. Psychological safety: the history, renaissance, and future of an interpersonal construct. Annu Rev Organ Psychol Organ Behav. 2014;1(1):23-43. doi:10.1146/annurev-orgpsych -031413-091305

17. Moher D, Liberati A, Tetzlaff J, Altman DG. Preferred reporting items for systematic reviews and meta-analyses: the PRISMA statement. PLoS Med. 2009;6(7):e1000097. doi:10.1371/journal. pmed.1000097
18. Liberati A, Altman D, Tetzlaff J, et al. The PRISMA statement for reporting systematic reviews and meta-analyses of studies that evaluate health care interventions: explanation and elaboration. $J$ Clin Epidemiol. 2009;62(10)e1-34.

19. Hong QN, Fàbregues S, Bartlett G, et al. The Mixed Methods Appraisal Tool (MMAT) version 2018 for information professionals and researchers. Educ Inf. 2018;34(4):285-291. doi:10.3233/EFI-180221

20. Pace R, Pluye P, Bartlett G. Testing the reliability and efficiency of the pilot Mixed Methods Appraisal Tool (MMAT) for systematic mixed studies review. Int $J$ Nurs Stud. 2012;49(1):47-53. doi:10.1016/j.ijnurstu.2011.07.002

21. Choi J, Tate JA, Son YJ. Challenges experienced by family caregivers of the adult intensive care unit patients in Korea: an integrative review. Clin Nurs Res. 2020;1-19. doi:10.1177/1054773820918433

22. Crowley J, Ball L, Hiddink GJ. Nutrition in medical education: a systematic review. Lancet Planet Health. 2019;3(9):e379-e389. doi:10.1016/S2542-5196(19)30171-8

23. Hlongwa M, Mashamba-Thompson T, Makhunga S, Muraraneza C, Hlongwana K. Men's perspectives on HIV self-testing in sub-Saharan Africa: a systematic review and meta-synthesis. BMC Public Health. 2020;20(1):66. doi:10.1186/s12889-020-8184-0

24. Leenen JP, Leerentveld C, van Dijk JD, van Westreenen HL, Schoonhoven L, Patijn GA. Current evidence for continuous vital signs monitoring by wearable wireless devices in hospitalized adults: systematic review. J Med Internet Res. 2020;22(6):e18636. doi:10.2196/18636

25. Okuyama A, Nakagami-Yamaguchi E, Hayakawa K. Exploring nurses' speaking-up attitudes and behaviours: a cluster analysis study. J Med Saf. 2015;2015.

26. Omura M, Stone TE, Levett-Jones T. Cultural factors influencing Japanese nurses' assertive communication. Part 1: collectivism. Nurs Health Sci. 2018;20(3):283-288. doi:10.1111/nhs.12411

27. Omura M, Stone TE, Levett-Jones T. Cultural factors influencing Japanese nurses' assertive communication: part 2 - hierarchy and power. Nurs Health Sci. 2018;20(3):289-295. doi:10.1111/nhs.12418

28. Omura M, Stone TE, Maguire J, Levett-Jones T. Exploring Japanese nurses' perceptions of the relevance and use of assertive communication in healthcare: a qualitative study informed by the theory of planned behaviour. Nurse Educ Today. 2018;67:100-107. doi:10.1016/j.nedt.2018.05.004

29. Han J. A structure model of clinical nurses' silence on patient safety. J Korean Acad Fundam Nurs. 2018;25(1):68-77. doi:10.7739/jkafn.2018.25.1.68

30. Kim M, Oh S, Alexander S. Assimilating to hierarchical culture: a grounded theory study on communication among clinical nurses. PLoS One. 2016;11(6):e0156305. doi:10.1371/journal.pone.0156305

31. Kim MY, Kang S, Kim Y, You M. Nurses' willingness to report near misses: a multilevel analysis of contributing factors. Soc Behav Pers. 2014;42(7):1133-1146. doi:10.2224/sbp.2014.42.7.1133

32. Law BYS, Chan EA. The experience of learning to speak up: a narrative inquiry on newly graduated registered nurses. $J$ Clin Nurs. 2015;24(13-14):1837-1848. doi:10.1111/jocn.12805

33. Chang WY, Hsu C-T, Yu PY. Confidence is the plant of slow growth: a moderated mediation model for predicting voice behavior among power distance orientation and team-based self-esteem in Taiwanese nurses. Psychol Res Behav Manag. 2019;12:609-617. doi:10.2147/ PRBM.S209931

34. Horak S, Yang I. Whither seniority? Career progression and performance orientation in South Korea. Int J Hum Resour Manag. 2019;30 (9):1419-1447. doi:10.1080/09585192.2017.1362659

35. Claramita M, Susilo AP. Improving communication skills in the Southeast Asian health care context. Perspect Med Educ. 2014;3 (6):474-479. doi:10.1007/s40037-014-0121-4

36. Joong-Hwan O, Kim HS, Lee JH. Asian cultural collectivism, acculturation, and life satisfaction among ethnic Asian brides in South Korea. Asian Women. 2014;30(3):23-56. doi:10.14431/ aw.2014.09.30.3.23 
37. Bogosian R. The intersection of national cultural values and organizational cultures of silence and voice, and the moderating effect of leadership. Acad Int Bus. 2018;18(2):16-20.

38. Edmondson AC. The Fearless Organization: Creating Psychological Safety in the Workplace for Learning, Innovation, and Growth. Hoboken: John Wiley \& Sons; 2018.

39. Edmondson AC. Psychological safety and learning behavior in work teams. Adm Sci Q. 1999;44(2):350-383. doi:10.2307/2666999

40. O'donovan R, Mcauliffe E. A systematic review of factors that enable psychological safety in healthcare teams. Int $J$ Qual Health Care. 2020;32(4):240-250. doi:10.1093/intqhc/mzaa025

41. Carmeli A, Reiter-Palmon R, Ziv E. Inclusive leadership and employee involvement in creative tasks in the workplace: the mediating role of psychological safety. Creat Res J. 2010;22(3):250-260. doi:10.1080/10400419.2010.504654

42. Nembhard IM, Edmondson AC. Making it safe: the effects of leader inclusiveness and professional status on psychological safety and improvement efforts in health care teams. J Organ Behav. 2006;27 (7):941-966. doi:10.1002/job.413

43. Willis CD, Saul J, Bevan H. Sustaining organizational culture change in health systems. $J$ Health Organ Manag. 2016;30(1):2-30. doi:10.1108/JHOM-07-2014-0117

44. Friedman R, Hong YY, Simons T, Chi SC, Oh SH, Lachowicz M. The impact of culture on reactions to promise breaches: differences between East and West in behavioral integrity perceptions. Group Organ Manag. 2018;43(2):273-315. doi:10.1177/1059601116678101

45. Yoshinaga N, Nakamura Y, Tanoue H, MacLiam F, Aoishi K, Shiraishi Y. Is modified brief assertiveness training for nurses effective? A single-group study with long-term follow-up. J Nurs Manag. 2018;26(1):59-65. doi:10.1111/jonm.12521

46. Omura M, Maguire J, Levett-Jones T, Stone TE. The effectiveness of assertiveness communication training programs for healthcare professionals and students: a systematic review. Int $J$ Nurs Stud. 2017;76:120-128. doi:10.1016/j.ijnurstu.2017.09.001

47. Küçükdeveci AA, Sahin H, Ataman S, Griffiths B, Tennant A. Issues in cross-cultural validity: example from the adaptation, reliability, and validity testing of a Turkish version of the Stanford Health Assessment Questionnaire. Arthritis Care Res. 2004;51(1):14-19. doi:10.1002/art.20091
48. Swami V, Barron D. Translation and validation of body image instruments: challenges, good practice guidelines, and reporting recommendations for test adaptation. Body Image. 2019;31:204-220. doi:10.1016/j.bodyim.2018.08.014

49. Leonard M, Graham S, Bonacum D. The human factor: the critical importance of effective teamwork and communication in providing safe care. Qual Saf Health Care. 2004;13(Suppl suppl_1):i85-90. doi:10.1136/qshc.2004.010033

50. Lyndon A, Sexton JB, Simpson KR, Rosenstein A, Lee KA, Wachter RM. Predictors of likelihood of speaking up about safety concerns in labour and delivery. BMJ Qual Saf. 2012;21(9):791-799. doi:10.1136/bmjqs-2010-050211

51. McVanel S, Morris B. Staff's perceptions of voluntary assertiveness skills training. J Nurses Staff Dev. 2010;26(6):256-259. doi:10.1097/ NND.0b013e31819b5c72

52. Dyne LV, Ang S, Botero IC. Conceptualizing employee silence and employee voice as multidimensional constructs. J Manag Stud. 2003;40(6):1359-1392. doi:10.1111/1467-6486.00384

53. Tangirala S, Ramanujam R. Employee silence on critical work issues: the cross level effects of procedural justice climate. Pers Psychol. 2008;61(1):37-68. doi:10.1111/j.1744-6570.2008.00105.x

54. Sayre MM, McNeese-Smith D, Leach LS, Phillips LR. An educational intervention to increase "speaking-up" behaviors in nurses and improve patient safety. J Nurs Care Qual. 2012;27(2):154-160. doi:10.1097/NCQ.0b013e318241d9ff

55. Fuller JB, Barnett T, Hester K, Relyea C, Frey L. An exploratory examination of voice behavior from an impression management perspective. J Manag Issues. 2007;19(1):134-151.

56. Wu W, Tang F, Dong X, Liu C. Different identifications cause different types of voice: a role identity approach to the relations between organizational socialization and voice. Asia Pac J Manag. 2015;32(1):251-287. doi:10.1007/s10490-014-9384-x

57. Van Dyne L, LePine JA. Helping and voice extra-role behaviors: evidence of construct and predictive validity. Acad Manage J. 1998;41(1):108-119.
Risk Management and Healthcare Policy

\section{Publish your work in this journal}

Risk Management and Healthcare Policy is an international, peerreviewed, open access journal focusing on all aspects of public health, policy, and preventative measures to promote good health and improve morbidity and mortality in the population. The journal welcomes submitted papers covering original research, basic science, clinical \& epidemiological studies, reviews and evaluations, guidelines, expert opinion and commentary, case reports and extended reports. The manuscript management system is completely online and includes a very quick and fair peer-review system, which is all easy to use. Visit http://www.dovepress.com/testimonials.php to read real quotes from published authors. 